\title{
THE EFFECT OF SACCHARIDES ON LEUKOCYTE MOVEMENT ${ }^{1}$
}

\author{
BY ANDREW KUNA 2 AND ROBERT CHAMBERS \\ (From the Department of Biology, Washington Square College of Arts and Science, New York \\ University, New York, N. Y.)
}

(Submitted for publication November 14, 1952; accepted January 21, 1953)

\section{INTRODUCTION}

The movement of leukocytes has been associated with the presence of attracting substances since Leber (1) found evidence of a chemotactic agent in rabbit cornea previously irritated with dead staphylococci. He found that leukocytes moved in straight lines from all directions to the irritated area. Since these early experiments, technics have been refined and many substances have been reported to attract leukocytes, including, inter alia, bacteria (2), histamine (3), polypeptides (4), starch (5) and sugars (6).

Moreover, various distances of attraction have been reported. For example, staphylococci have been claimed to attract granulocytes from a distance as great as $1.0 \mathrm{~mm}$. (7), while starch attracted granulocytes from a distance of $0.2 \mathrm{~mm}$. (8).

Leukocytes are prone to considerable variations under different physiological conditions. For example, narcotized cells do not exhibit chemotactic behavior. Moreover, some species of virulent bacteria when phagocytosed are capable of destroying the protoplasm of granulocytes (9). Investigators of chemotaxis have emphasized the attracting substance, but have failed to consider the source and physiological status of the granulocytes. The study of chemotactic reactions of granulocytes under carefully controlled conditions should help toward the solution of the mechanisms involved in this phenomenon.

This work was undertaken for the purpose of studying chemotactic behavior of granulocytes obtained from animals maintained under controlled conditions. The neutrophilic granulocytes were the cells considered, but reference is sometimes made to them as leukocytes or white blood cells.

\footnotetext{
1 A dissertation in the Department of Biology submitted to the Faculty of the Graduate School of Arts and Science of the New York University in partial fulfillment of the requirements for the degree of Doctor of Philosophy.

2 Present address: Northport Veterans Administration Hospital, Northport, New York.
}

MATERIAL AND METHODS

\section{A. Material}

1. Animals. Adult rats of the Wistar strain weighing between 250 to $350 \mathrm{~g}$. were used throughout the experiments, except in instances where repetition of other investigators' procedures was necessary. The animals were kept in as uniform a condition as possible. In order to avoid undue excitement when being prepared for experiments, the rats were handled frequently. For the same reason, the males were separated from the females.

The diet for the fed animals consisted of Purina dog chow and a semiweekly supplement of fresh green vegetables. Some of the animals were unfed for 36 hours, and others for five to six days before experimentation. When animals were unfed for long periods, they were isolated to prevent cannibalism. Water, however, was available at all times.

2. Plasma. Blood was obtained either from the normal or unfed rat by a heart puncture with a No. 21 gauge sterile needle attached to a $10 \mathrm{cc}$. Luer syringe which contained $0.2 \mathrm{cc}$. barium heparinate solution for each $10 \mathrm{cc}$ of blood (35 mg. crystalline barium heparinate dissolved in $15 \mathrm{cc}$. normal saline). The needle was removed from the syringe and the blood slowly expelled into a sterile $15 \mathrm{cc}$. centrifuge tube. The plasma was obtained by centrifuging for five minutes at $6500 \times \mathrm{G}$. The supernatant plasma was removed by pipette transfer.

The clotting time of the supernatant heparinized plasma was determined by mixing one drop of the plasma with one drop of thromboplastin solution (see below). The time of formation of the clot was established by picking at the edges of the mixture with a dissecting needle at intervals of 10 seconds until a stringiness was noted. This procedure produced a clot which was not too rigid and therefore offered no obstacle for the migrating granulocytes, and yet had sufficient consistency to prevent dislocation of granulocytes by convection currents. The granulocytes in these preparations exhibited good amoeboid movement.

The plasma used in these experiments had a clotting time of approximately two minutes. This enabled completion of the entire slide-cover-slip preparation before clotting occurred.

3. Granulocytes. In order to obtain the granulocytes, the animals were first injected intraperitoneally with 20 cc. of sterile normal saline. Intraperitoneal injections of saline were performed at the same time of day. No anaesthetics were used, since their narcotizing effects might invalidate the results. Three hours after the intraperitoneal injections of saline, the rat was killed by heart puncture 
exsanguination, the peritoneal cavity immediately opened, and the fluid therein removed with a special pipette and transferred to a sterile $15 \mathrm{cc}$. tube. The special pipette, fitted with a rubber bulb, had a tip opening of approximately $1 \mathrm{~mm}$. This comparatively large opening was used to prevent possible damage to the granulocytes. Exsanguination prevented the contamination by blood of the peritoneal fluid containing the granulocytes.

The granulocytes were studied under two conditions: $a)$ free granulocytes; and $b$ ) agglutinated granulocytes. The free granulocytes were obtained by placing a drop of the suspension from the peritoneal cavity into a drop of plasma within 10 to 15 minutes after collection. For the agglutinated granulocytes, the peritoneal fluid was allowed to agglutinate in the tube by standing at room temperature for approximately one hour. A small portion of the agglutinated mass was separated and placed in the center of the tissue-culture medium.

4. Thromboplastin. Thromboplastin was prepared from the lungs of the same animal from which the granulocytes and plasma were obtained. The lungs, removed under aseptic conditions, were washed several times with sterile saline to remove traces of red cells. The washed lungs were then ground to a pulp in a sterile mortar with an equal amount of sterile, reagent grade sand. Ten cc. of sterile saline were added to the pulp and the mixture ground again. The resulting fine suspension was transferred to a sterile $15 \mathrm{cc}$. tube and centrifuged for five minutes at $6500 \times \mathrm{G}$. The supernatant solution, which contained the thromboplastin, was used to coagulate the plasma.

\section{B. Technic for Studying Chemotactic Behavior}

The method used for studying the activity of granulocytes was a modified combination of the slide-cover-slip procedure used by $\mathrm{McCutcheon}$ (7) and the tissue-culture technic worked out by Meier (2) and by Chambers and Grand (6).

The modified procedure was essentially as follows:

1. One drop of plasma was placed on a sterile slide. For nonagglutinated granulocyte preparations, a small drop of granulocyte suspension was added to the drop of plasma and stirred with a sterile needle.

2. In the agglutinated-granulocyte experiments, a small portion of the clumped mass was placed in the center of the plasma drop.

3. The substances to be tested were then added to the granulocyte-plasma medium. Solid particles, such as starch granules of approximately 0.2 to $0.4 \mathrm{~mm}$. in diameter, were sparingly sprinkled over the plasma preparation. The mixture was then gently agitated with a needle in order to coat the particles with plasma. Clotting was then induced with a drop of thromboplastin added to the preparation without agitation, and a sterile cover slip placed over the culture. The cover slip did not press down on the leukocytes since the starch granules acted as 2 support. After three minutes, the edges of the preparation were sealed with paraffin wax and the slides placed in an incubator maintained at $39^{\circ} \mathrm{C}$.
Glass microcapillaries with an outside diameter of approximately $0.1 \mathrm{~mm}$. were employed for the testing of plasma soluble substances on granulocyte movement. The procedure described for the use and preparation of microcapillaries by Chambers and Grand (6) was used.

In all experiments nonattracting, or indifferent, and attracting substances were included. Glycogen invariably attracted leukocytes while physiological saline produced no attraction. Therefore, these two substances were used as controls.

\section{EXPERIMENTAL PROCEDURE AND RESULTS}

\section{A. Agglutination of Granulocytes in Peritoneal Fluid}

The granulocytes were obtained from animals in three nutritional states : 1) well fed; 2) unfed for 36 hours; and 3) unfed for five to six days. The peritoneal fluid, ranging from 6 to $10 \mathrm{cc}$., was placed in sterile centrifuge tubes which were plugged with cotton and allowed to remain at room temperature. The changes that occurred in the suspension of granulocytes were the following:

1. Well-fed animals. No definite agglutination of granulocytes was noticed. After several hours most of the cells settled to the bottom of the tube in a loosely adherent state.

2. Animals unfed 36 hours. Definite tendency toward agglutination was noticed. Adhesion of one cell to another often occurred within $15 \mathrm{~min}$ utes. The cells massed into a cone shape, suspended in the center of the liquid medium. The entire mass could easily be removed from the tube and when two dissecting needles were used to separate pieces from the agglutinated mass, it was found that the cells adhered firmly to one another and could be separated only with difficulty.

3. Animals unfed five to six days. Tendency toward agglutination was not definite and after two to three hours the granuloyctes clumped in small hemorrhagic clusters which adhered to the sides of the tube and sometimes one large cluster would fall to the bottom.

\section{B. Attraction of Granulocytes by Various Sub- stances}

Tissue-culture preparations of granulocytes obtained from animals subjected to various nutritional conditions were made by using solid particles or dissolved substances placed in capillary tubes. Responses of the granulocytes were considered positive when the cells adhered to the solid particles being tested, and after making contact, spread out in a thin layer over the surface of the particle. Small objects engulfed by a single granulocyte 
were considered to be phagocytosed. When fluid-filled capillary tubes were used, the entry of granulocytes into open ends of the tubes was considered as a positive response. For substances showing no response, i.e., neither negative nor positive, the granulocytes did not adhere to, nor collect near, nor were they repulsed by, the substances being tested.

Six to eight capillary tubes were used for each preparation. One of the capillary tubes always contained glycogen, a known attracting substance, which acted as an index of the chemotactic behavior of the granulocytes. Whenever the granulocytes moved away from the area of a substance being tested, the behavior was considered a negative attraction. The following results were obtained :

1. Well-fed animals. Many substances failed to attract the granulocytes. Glucose elicited no response, but polysaccharides such as glycogen and starch always attracted the granulocytes. The rate of movement averaged approximately $20 \mathrm{mi}$ crons per minute. The response of granulocytes to various substances is summarized in Table $I$.

2. Animals unfed 36 hours. Granulocytes from unfed rats showed more activity and greater rate of movement than those obtained from well-fed rats. The rate of movement averaged approximately 30 to 40 microns per minute. A higher

TABLE I

Attraction of granulocytes *

\begin{tabular}{|c|c|c|c|}
\hline Substances tested & $\begin{array}{c}\text { Rats } \\
\text { well-fed }\end{array}$ & $\begin{array}{c}\text { Rats } \\
\text { unfed } \\
36 \text { hours }\end{array}$ & $\begin{array}{l}\text { Rats } \\
\text { unfed } 5 \\
\text { to } 6 \text { days }\end{array}$ \\
\hline $\begin{array}{l}\text { 1. Starch (potato) } \\
\text { 2. Starch (soluble) } \\
\text { 3. } 3 \text { and } 5 \% \text { Glycogen } \\
\text { 4. } 3 \text { and } 5 \% \text { Agar agar }\end{array}$ & $\begin{array}{l}\mathbf{x} \\
\mathbf{x} \\
\mathbf{x} \\
\mathbf{x}\end{array}$ & $\begin{array}{l}\mathbf{x} \\
\mathbf{x} \\
\mathbf{x} \\
\mathbf{x}\end{array}$ & $\begin{array}{l}0 \\
0 \\
0 \\
0\end{array}$ \\
\hline $\begin{array}{l}\text { I 5. } 3 \text { and } 5 \% \text { Glucose } \\
6.3 \text { and } 5 \% \text { Sucrose } \\
7.3 \text { and } 5 \% \text { Lactose } \\
\text { 8. } 3 \text { and } 5 \% \text { Maltose }\end{array}$ & $\begin{array}{l}\mathbf{0} \\
\mathbf{0} \\
\mathbf{0} \\
\mathbf{0}\end{array}$ & $\begin{array}{l}\mathbf{x} \\
\mathbf{x} \\
\mathbf{x} \\
\mathbf{x}\end{array}$ & $\begin{array}{l}\mathbf{0} \\
\mathbf{0} \\
\mathbf{0} \\
\mathbf{0}\end{array}$ \\
\hline $\begin{array}{l}\text { 9. } 3 \text { and } 5 \% \text { Gelatin } \\
\text { 10. Protein hydrolysates } \\
\text { (acid) }\end{array}$ & $\begin{array}{l}\mathbf{0} \\
\mathbf{0}\end{array}$ & $\begin{array}{l}\mathbf{0} \\
\mathbf{0}\end{array}$ & $\begin{array}{l}\mathbf{0} \\
\mathbf{0}\end{array}$ \\
\hline $\begin{array}{l}\text { 11. Protein hydrolysates } \\
\text { (enzyme) }\end{array}$ & $\mathbf{0}$ & $\mathbf{0}$ & $\mathbf{0}$ \\
\hline $\begin{array}{l}\text { 12. Blood plasma } \\
\text { 13. } 1: 1000 \text { Histamine } \\
\text { 14. } 1: 100 \text { Endotoxin from } \\
\text { pyrogenic bacteria }\end{array}$ & $\begin{array}{l}0 \\
0 \\
\mathbf{x}\end{array}$ & $\begin{array}{l}\mathbf{0} \\
\mathbf{0} \\
\mathbf{x}\end{array}$ & $\begin{array}{l}\mathbf{0} \\
\mathbf{0} \\
\mathbf{0}\end{array}$ \\
\hline $\begin{array}{l}\text { 15. } 3 \text { and } 5 \% \text { Lactic acid } \\
\text { 16. } 1 \% \text { Heparin } \\
\text { 17. Carbon particles } \\
\text { 18. Glass particles } \\
\text { 19. Physiological saline }\end{array}$ & $\begin{array}{l}- \\
\mathbf{0} \\
\mathbf{0} \\
\mathbf{0} \\
0\end{array}$ & $\begin{array}{l}- \\
0 \\
0 \\
0 \\
0\end{array}$ & $\begin{array}{l}\mathbf{0} \\
\mathbf{0} \\
\mathbf{0} \\
\mathbf{0} \\
\mathbf{0}\end{array}$ \\
\hline
\end{tabular}

* $x$ indicates positive attraction.

0 indicates no attraction.

- indicates negative attraction. percentage of starved granulocytes moved within a given time and many more pseudopodia were continually extended, giving the cells an irregular shape, instead of the tendency toward rounding, as observed in the apparently well-fed granulocytes.

3. Animals unfed five to six days. No attraction to substances was noted since the granulocytes showed only slight motility. Only a few granulocytes left the clumped mass and moved a distance not exceeding $1 \mathrm{~mm}$. after six hours of incubation.

No differences in behavior were noted between the agglutinated and nonagglutinated granulocytes.

\section{Movement of Granulocytes toward Starch Grains}

Starch grains were used as the attracting substance. The movement of nonagglutinated granulocytes after one hour of incubation was observed under the microscope equipped with a warm stage. The following results were obtained:

\section{Well-fed animals}

a) Granulocytes showed no directional movement except when reaching a distance approximately $0.1 \mathrm{~mm}$. from the periphery of the granule. Even within this area, many of the granulocytes reached the surface of the starch granule by random movement, while others showed a definite directional motion toward the attracting substance. When nonattracting substances such as carbon particles were used, directional motion was not observed at any distance from the surface of the carbon. When soluble starch was used, the area of attraction was found to be 0.7 to $1.0 \mathrm{~mm}$. from the surface of the starch granule. Rate of movement was from 10 to 25 microns per minute.

b) Granulocytes on reaching the surface of the starch granule either remained there and spread out, or else moved away from the granule.

c) Starch granules too large for phagocytosis were completely coated by a monolayer of granulocytes. Other granulocytes, on reaching the coated starch grains, moved away. Granulocytes which formed the monolayer would often detach themselves from the surface of the attracting substance. This happened after several hours of incubation. Other granulocytes would then occupy the un- 
covered areas of the starch. There was little adhesion of one granulocyte to another.

d) When the starch granules were removed from the preparation after the completion of the experiment and studied under high power, it was noted that small grooves were present on the originally smooth surfaces. Grooves were not apparent in similar preparations containing no granulocytes.

2. Animals unfed 36 hours. A monolayer of granulocytes was also produced on the starch grains, but when other granulocytes came into contact with the cells forming the monolayer, adhesion occurred, thereby resulting in the accumulation of a large mass of cells. Other observations were similar to those obtained in the experiments on the attraction of granulocytes by various substances.

3. Animals unfed five to six days. Results were similar to those on attraction of granulocytes by various substances.

\section{Movement of Granulocytes from a Clumped Mass}

Six capillary tubes filled with soluble material were used for each preparation. The positions of attracting and nonattracting substances were varied. For example, in some preparations three nonattracting capillary tubes were placed on one side of the granulocyte mass, and three attracting substances on the other. In other preparations, both attracting and nonattracting capillary tubes were placed on one side. In some, the attracting capillary tube was flanked by two nonattracting capillaries; in others, one nonattracting capillary was flanked by two attracting capillary tubes. After one hour of incubation, the movements of agglutinated granulocytes were observed on a warm stage. The following results were obtained:

\section{Well-fed animals}

a) The rate of movement was the same for both attracting and nonattracting substances.

b) The granulocytes always moved away from the clumped mass so that a directional movement existed whether an attracting substance was present or not.

c) After six to eight hours a complete circle of outwandering cells was found, extending 4 to 6 $\mathrm{mm}$. away from the periphery of the clumped mass.

d) The attracting substances showed no greater influence on the directional movement than did the nonattracting substances. e) Granulocytes, on reaching the surface of the particular attracting substance, either remained there, spread out in a thin layer, or moved away. On the other hand, the granulocytes never spread out on the nonattracting particles, but always moved away. In nearly all instances granulocytes collected in large numbers inside the capillary tubes which contained attracting substances.

2. Animals unfed 36 hours. The results were essentially the same as with granulocytes obtained from well-fed animals except that the movements were more rapid ( 35 to 40 microns per minute), more pseudopodia were present and the granulocytes became massed around the attracting substances.

3. Animals unfed five to six days. The granulocytes showed no tendency toward motion, and after six hours only a small number of cells had left the clumped mass, and these had traveled only a distance of approximately $1 \mathrm{~mm}$. Furthermore, the number of granulocytes was smaller than from well-fed and 36 hour unfed rats, and red cells were always found intermingled with the white cells.

\section{DISCUSSION}

The experiments described in this paper offer a clue to the results of Chambers and Grand (10) and the discrepancy presented by $\mathrm{McCutcheon}$ (7) in his review. Sheldon, in a personal communication, cited by $\mathrm{McCutcheon}$, did not state the condition of the animals used as the source of his material. The results reported in this paper would indicate that the animals, as used by Sheldon, were not starved. Chambers and Grand, however, used as their culture medium the plasma from roosters which had been starved for 48 hours for the purpose of eliminating fat from the plasma.

The question now encountered is : Why do polysaccharides attract granulocytes from both well-fed and starved animals while only the latter are attracted by mono- and disaccharides? Granulocytes from the starved animals are attracted by glucose, other sugars and polysaccharides in vitro, but granulocytes from well-fed animals show attraction for polysaccharides only.

Granulocytes seem to be attracted preferentially by polysaccharides, since granulocytes from both starved and well-fed animals are attracted to glycogen and starch. This may suggest a metabolic 
preference. Glucose is always present, although in variable amounts, in the blood stream. It is only when the store of glucose in the blood stream has been lowered to the starvation level (approximately $70-80 \mathrm{mg} . \%$ ) that the granulocytes are attracted by glucose in vitro. The problem concerning the preference of granulocytes for polysaccharides may also be attacked from the point of view of energy and metabolism. Polysaccharides probably present a more economical pathway for the cells. Polysaccharides such as glycogen and starch are more directly fermentable since phosphorolysis does not depend upon a high accumulation of adenosine triphosphate (11).

That nutritional environment plays a role in immunity has been reported by Sprunt (12) who has shown that prolonged fasting may cause a tenfold increase in the normal antiviral resistance in rabbits. Richardson (13) determined the phagocytic power of leukocytes of diabetic patients and depancreatized cats with acidosis or those with uncontrolled diabetes. In both situations, a significant decrease occurred in the phagocytic power. Also, one of the first reactions of the body toward infection and fever is a loss of appetite which might starve granulocytes, thus making them more active. In diabetics with high blood sugar, granulocytes have an abundant supply of glucose. The experiments in this paper indicate that granulocytes from well-fed animals are slow-moving and less "sticky" than the granulocytes from unfed animals. Furthermore, the results show that granulocytes from starved animals move more rapidly and are much more adhesive to one another. Granulocytes from well-fed animals frequently move away after making contact with either glycogen or starch, which seem to be the preferred nutritional substances. A granulocyte from a fasting animal, however, adheres to glycogen or starch, spreads over the surface of these substances and, if the particles are small enough, completely ingests them. Kuna, Blattberg and Reiman (14) showed that leukocytes obtained from rats well-fed for four weeks prior to a 36 hour period of starvation, when compared with leukocytes from continuously well fed animals, showed twice the percentage of phagocytosing white blood cells which engulfed three times the number of bacteria.

Some investigators have shown an increase and others a decrease in the phagocytic index with a reduction of food intake. Mills and Cottingham (15) found a relationship between protein consumption and phagocytosis. Rats lost weight the first week on a deficient diet, but the blood phagocytes did not become less active until the second week, and the lowest level of phagocytosis was reached at the end of the fourth week.

In rats fed a grossly deficient diet, Berry, Davis and Spies (16) measured a decrease in the phagocytic activity of neutrophiles as compared to that in animals on an adequate diet. Columbo (17) noted a moderate increase in complement accompanying malnutrition in children. The phagocytic titers were frequently elevated. Berry, Davis and Spies (18) noticed that in cases of all types of anemia an increase in neutrophilic activity was found and the magnitude of the effect was roughly proportional to the severity of the anemia. Berry, Leyendecker and Spies (19) also found increased phagocytic activity of neutrophiles in blood, measured in vitro, of patients with anemia, many of whom were malnourished. As stated by these authors, "Such an apparent increase in phagocytic activity in anemia was particularly surprising, since many of the persons whose blood was studied were malnourished." More recently, Gordon and Katsh (20) have shown that chronic starvation, induced in normal animals, resulted in a greatly increased uptake of thorium dioxide by the spleen.

Some of the contradictions in the literature may be explained by defining the conditions under which the experiments were performed. Activity of neutrophiles and phagocytosis decreases with undernourishment, i.e., elimination of one or more essential nutritional elements for an extended period of time. Phagocytosis and neutrophile activity are increased in an animal which had been maintained in a good nutritional state prior to a 36 hour starvation period. The term "subnutritional phagocytosis" has been suggested for this phenomenon (21). However, if the starvation period of a previously well-nourished animal is extended to five or six days, the neutrophile activity decreases to almost nil with consequent decrease in phagocytosis possibly resulting in greater susceptibility to infection.

Further evidence can be presented to show that the action of granulocytes is subject to environmental conditions. It is possible that one of the 
main factors concerning this attraction of granulocytes to bacteria is that bacteria are frequently coated with polysaccharides. A negative chemotaxis may result if bacteria coated with polysaccharides also produce toxins which are harmful to the granulocytes. However, when such toxins are neutralized by antibodies, the granulocytes are attracted to the bacteria (22).

Preliminary work in this investigation on the attraction of granulocytes by acids has shown that a $\mathrm{pH}$ below 6.7 causes a negative attraction or death if the granulocyte cannot move away. Thus, it seems that granulocytes avoid a harmful environment and accumulate in areas containing preferred metabolic substances, such as glycogen. Lactic acid, which is detrimental to leukocytic activity, repels and, conversely, glycogen, which is a probable nutrient for granulocytes, exhibits positive attraction.

The mechanisms involved in granulocytic migration are varied. If the starch granule (too large to be phagocytosed) was used as the attracting substance, it was found that attraction for granulocytes occurred 0.1 to $0.2 \mathrm{~mm}$. from the surface of insoluble starch. However, soluble starch showed an area of attraction ranging from 0.5 to $0.7 \mathrm{~mm}$. This suggests that a concentration gradient may be a factor in attracting granulocytes toward starch. It is only within the zone of a concentration gradient that granulocytes move toward the starch grain. Elsewhere the movement is random. Granulocytes from well-fed animals did not always show the attraction for starch grains even within the concentration gradient zone. Some moved at right angles to the substance and some even moved away from the substance.

Granulocytes from unfed animals showed a decided movement toward the starch granule when within the concentration gradient zone. After a few hours when the granulocytes moved away, some erosion of the starch grains could be seen, suggesting a possible utilization of some starch by the granulocytes. This phenomenon was observed by both authors independently.

Experiments in this paper have shown that the movements of granulocytes from an agglutinated mass is always in a definite direction away from the mass. This directional movement is the same whether an attracting or a nonattracting substance is present. Moreover, if a capillary tube is placed tangentially to the agglutinated mass, the granulocytes will collect on the sides of the capillary because their motion has been impeded by this obstruction.

It seems that the true indication of attraction may not only be the contact of the substance by the granulocytes, but also the adherence and the spreading of the granulocytes over the substance.

It is evident that agglutination of granulocytes varies with the nutritional state of the animals from which the granulocytes were obtained. Thus granulocytes from well-fed animals started to adhere to the walls of the tube, but, since they were not sticky, fell to the bottom. From animals unfed for 36 hours, the granulocytes were "sticky" and formed complete cone-shaped masses in the center of the liquid. No adhesion to the sides of the tube was noted. From animals unfed for five to six days, the agglutination was less evident, but individual masses of granulocytes intermixed with erythrocytes adhered to the sides of the tube. The clumped mass from the 36 hour-unfed animals was the hardest to separate into smaller pieces. It seems probable that moderate starvation rendered the granulocytes sticky so that they adhered very easily to nutritive substance. This may account for the accumulation around an attracting substance.

Glycogen seems to be the most likely substance for the attraction of granulocytes. Irritations which produce a tissue breakdown liberate, among other things, glycogen. The insertion of a piece of sterile steel subcutaneously could liberate glycogen from broken cells and thus promote attraction for granulocytes almost immediately. Since only very small quantities of glycogen are required for attraction, it is possible that exudates from inflammations do contain glycogen and that glycogen may be the active principle and not necessarily a polypeptide, as postulated by Menkin (23). Many simple polypeptides which have been tested did not attract granulocytes.

The phenomenon of sub-nutritional resistance apparently occurs in previously well-fed animals deprived of food for 36 to 48 hours, with a blood sugar level between 70 and $80 \%$. In diabetics it does not suffice to reduce blood sugar to so-called normal levels of 120 to $140 \mathrm{mg}$. \% to increase resistance. It is necessary to lower the blood sugar to the fasting level of 70 to $80 \mathrm{mg}$. \% in order to produce increased leukocyte activity. Thus a dia- 
betic treated pre-operatively with sufficient insulin to lower the blood sugar to a fasting level should show greater resistance to infection.

The experimental evidence presented indicates that it is the granulocytes as well as the substance which must be considered in all types of granulocyte activity. Reaction to the environment by the cells may very well be the key to the mechanisms involved in their action.

\section{SUM MARY}

1. Methods utilizing tissue-culture procedures were developed for studying the behavior of granulocytes obtained from rats subjected to varying degrees of underfeeding.

2. Granulocytes obtained from rats unfed for 36 hours had a stronger tendency to agglutinate than those obtained from rats unfed for five to six days. However, granulocytes from well-fed rats did not agglutinate to any appreciable extent.

3. Starch particles too large to be ingested were frequently coated by a single layer of granulocytes obtained from well-fed rats. Granulocytes obtained from rats unfed 36 hours showed a tendency to form many layers around the starch grains.

4. Starting with a clumped mass of granulocytes, the individual cells obtained from well-fed rats always moved away from the clumped mass, regardless of the presence of attracting or nonattracting substances nearby. Granulocytes obtained from rats unfed for 36 hours behaved similarly, except that their movements were more rapid. By contrast, granulocytes from rats unfed for five to six days rarely moved to any appreciable extent from a clumped mass.

5. Granulocytes from well-fed rats were always attracted by glycogen or starch, but not by monoor disaccharides. Granulocytes from animals unfed for 36 hours were attracted by polysaccharides as well as by mono- and disaccharides. No appreciable attraction of granulocytes was elicited by starch when these cells were obtained from rats unfed five or more days.

6. The possibility that glycogen is the natural granulocyte-attracting agent released on injury of tissue is discussed.

7. Movement of granulocytes was considered random at all times except in instances where granulocytes from rats starved for 36 hours were within a possible concentration gradient zone of an attracting substance.

\section{ACKNOWLEDGMENTS}

The authors wish to express their appreciation to Prof. H. A. Charipper and Prof. M. J. Kopac for their helpful criticism and for making this paper possible.

\section{REFERENCES}

1. Leber, $T$., Uber die Entstehung der Entzündung und die Wirkung der entzündungserregenden Schädlichkeiten. Forschr. d. Med., 1888, 6, 460.

2. Meier, R., Uber den Einfluss entzüngserregender Einwirkungen auf Bewegung, Wachstum und Stoffwechsel isolierter Zellen und Gewebe. Beitrag zur Analyse der cellularären Reaktionen beim Entzündungsvorgang. Ztschr. f. d. ges. exper. Med., 1933, 87, 283.

3. Wolf, E. P., Experimental studies on inflammation. 1. The influence of chemicals upon the chemotaxis of leucocytes, in vitro. J. Exper. Med., 1921, 34, 375.

4. Menkin, V., The role of inflammation in immunity. Physiol. Rev., 1938, 18, 366.

5. Coman, D. R., Chemotaxis of monocytes contrasted with that of polymorphonuclear leukocytes and lymphocytes. Arch. Path., 1940, 30, 896.

6. Chambers, R., and Grand, C. G., The chemotactic reaction of leucocytes to foreign substances in tissue culture. J. Cell. \& Comp. Physiol., 1936, 8, 1.

7. McCutcheon, M., Chemotaxis in leukocytes. Physiol. Rev., 1946, 26, 319.

8. Commandon, J., Tactisme produit par l'amidon sur les leucocytes. Enrobement du charbon. Compt. rend. Soc. de biol., 1919, 82, 1171.

9. Pokrovskaya, M. P., and Makarov, M. S., The relation of the wound exudate to healing. Am. Rev. Soviet Med., 1945, 2, 513.

10. Grand, C. G., and Chambers, R., The chemotactic reaction of leucocytes to irritated tissues. J. Cell. \& Comp. Physiol., 1936, 9, 165.

11. Leibowitz, J., and Hestrin, S., Alcoholic fermentation of the oligosaccharides, in Advances in Enzymology. Interscience Press, New York, 1945, 5, 87.

12. Sprunt, D. H., Effect of undernourishment on the susceptibility of the rabbit to infection with vaccinia. J. Exper. Med., 1942, 75, 297.

13. Richardson, R., Immunity in diabetes. IV. Measurements of phagocytic activity in diabetes mellitus. Am. J. M. Sc., 1942, 204, 29.

14. Kuna, A., Blattberg, B., and Reiman, J., Effect of starvation on phagocytosis "in vivo." Proc. Soc. Exper. Biol. \& Med., 1951, 77, 510.

15. Mills, C. A., and Cottingham, E., Phagocytic activity as affected by protein-intake in heat and cold. $\mathrm{J}$. Immunol., 1943, 47, 503. 
16. Berry, L. J., Davis, J., and Spies, T. D., The relationship between diet and the mechanisms for defense against bacterial infections in rats. J. Lab. \& Clin. Med., 1945, 30, 684.

17. Colombo, G. (Turin), Il potere complementare, il potere battericida ed il potere fagocitario nei lattanti affetti da malatti della nutrizione. Gior. di batteriol. e. immunol., 1939, 22, 463.

18. Berry, L. J., Davis, J., and Spies, T. D., Phagocytic activity of neutrophiles in anemias. J. Lab. \& Clin. Med., 1945, 30, 910.

19. Berry, L. J., Leyendecker, R. M., and Spies, T. D., Comparative studies of phagocytosis in normal and anemic blood. Blood; Morphologic Hematology, Special Issue No. 1, 1947, p. 98.

20. Gordon, A. S., and Katsh, G. F., The relation of the adrenal cortex to the structure and phagocytic activity of the macrophagic system. Ann. N. Y. Acad. Sc., 1949, 52, 1.

21. Editorial Comment, J.A.M.A., Nov. 24, 1951.

22. Stevenson, J. W., and Reed, G. B., Chemotactic response to staphylococcus strains of varying pathogenicity. J. Bact., 1940, 40, 239.

23. Menkin, V., Mechanism of inflammation. Arch. Path., $1937,24,65$. 